\title{
MINIMIZATION OF SHIELDING EFFECTIVENESS OF ENERGY SAVING WINDOWS IN WiFi FREQUENCY RANGE
}

\author{
E. Bilotas, P. Ragulis, and Ž. Kancleris \\ Department of Physical Technologies, Center for Physical Sciences and Technology, Sauletekio 3, \\ 10257 Vilnius, Lithuania \\ Email: evaldas.bilotas@ftmc.lt; paulius.ragulis@ftmc.lt
}

Received 18 April 2018; revised 31 May 2018; accepted 21 June 2018

\begin{abstract}
We investigated the dependence of shielding effectiveness of energy saving double-glazed windows on their longitudinal dimensions (thickness of metalized and uncoated glass panes and the gap between them) both experimentally and theoretically. It was shown that by changing the longitudinal dimension of the window the minimum of shielding effectiveness could be shifted to the desirable frequency range. Applying this approach to the WiFi frequency range we demonstrated that shielding effectiveness can be decreased by 7-9 dB for the $2.4 \mathrm{GHz}$ WiFi connection and by $14-17 \mathrm{~dB}$ for the $5 \mathrm{GHz}$ connection in comparison with that of an ordinary energy saving double-glazed window. Theoretical considerations have been confirmed by experimental investigation of the dependence of shielding effectiveness on the gap between glass panes.
\end{abstract}

Keywords: energy saving windows, shielding effectiveness, microwave propagation, WiFi, Fabry-Perot resonance

PACS: $87.50 . \mathrm{S}-$, 07.50.Hp, $42.25 . \mathrm{Bs}, 42.25 . \mathrm{Hz}$

\section{Introduction}

In the past ten years energy-efficient buildings became very popular, especially in northern countries, where $40 \%$ of energy is used for heating of buildings [1], 2]. Various methods have been introduced in order to increase thermal insulation. Using glass wool to insulate walls is one of the easiest ways to increase energy efficiency in older buildings. Considering thermal insulation, the great challenge is a huge surface area covered by window panes in most office and contemporary apartment buildings because basic windows are poor insulators. Therefore in order to increase energy efficiency of these modern buildings it was necessary to develop window panes with a high thermal insulation. For this purpose the low emission (Low-E) coating for glass has been developed. It consists of several layers of metal and metal oxide that form a conductive layer tens of nanometres thick [3]. This layer reflects most of the infrared radiation and keeps warmth from getting out during winter while preventing heat from coming in during summer [4]. Only by implementing Low-E windows, heating and conditioning costs can be greatly reduced [5].

Later it was realized that the metal coating reflects not only infrared radiation, but it also influences propagation of electromagnetic waves in the microwave frequency range. An in-depth theoretical analysis on single, double and laminated shields was made by Schulz et al. in 1988 [6]. It was found that these coatings can attenuate microwaves up to $50 \mathrm{~dB}$ in a range of 1 to $12 \mathrm{GHz}$ frequency [7]-9]. This means that mobile communication frequencies, GPS and WiFi, can be highly attenuated by Low-E windows [2, 10, 11]. This value becomes comparable to wall materials used in 
building construction [12]. Wooden walls can attenuate microwave radiation in the order of $10 \mathrm{~dB}$, while attenuation of reinforced concrete walls can be as high as $70 \mathrm{~dB}$. Some research has been made to analyse the influence of the metal grain size and distribution [13] or surface conductivity [14] on shielding effectiveness (SE), optical and near-infrared transmission properties. Frequency selective surfaces (FSS) were introduced as one of possible solutions for the reduction of SE [ [4, 15, 16, of Low-E windows. To realize FSS, a conductive layer is removed at specific places forming a particular geometrical pattern, which acts as a band pass filter for desirable frequencies [11, 17]. Another possibility to control SE is by changing the thickness of glass panes or the distance between them. Some theoretical research has been done on this matter analysing changes of SE in uncoated double and triple window panes [18]. In the present paper we discuss the possibility of minimization of $\mathrm{SE}$ at WiFi frequencies.

It is achieved by changing longitudinal dimensions (thickness of glass panes and the distance between them) of a double-glazed window pane with one coated glass. We investigated the most common 2.4 and $5 \mathrm{GHz}$ WiFi frequency bands. Calculations and experiments were conducted on the commercially produced Low-E glass which was incorporated into a double-glazed window pane.

This paper is organized as follows. In the next Section, the measurement technique and construction of the samples are presented. In Section 3 , the matrix multiplication method for the SE calculation of any number of dielectrics covered with a thin conductive layer is briefly described. Afterwards, the reader is provided with the modelled and measured SE characteristics for different longitudinal dimensions of the window. Then the window panes with optimized longitudinal dimensions showing the lowest SE at WiFi frequencies are presented and compared with frequency selective structures. This paper ends with the conclusions concerning the possibilities to control the SE of energy saving windows.

\section{Measurement setup and sample design}

In order to estimate the dependence of SE on the gap between the glass panes, measurements of Low-E windows were performed in an anechoic chamber. There are several other methods for measuring SE which include either close proximity experiments [7, 10] or measurements in a reverberation chamber [ [ , 19]. The former method has a high measurement error because multiple reflections occur between antennas standing tenths of centimetres from each other. The latter method can only be used to measure SE averaged over all incidence angles of electromagnetic radiation at once. This means that it is impossible to measure resonances for specific angles of radiation. Therefore, the best results in our case can be gained by measuring in an anechoic chamber, at a normal angle of incidence.

The experiment setup is shown in Fig. 1. The aperture in the metal wall of the anechoic chamber

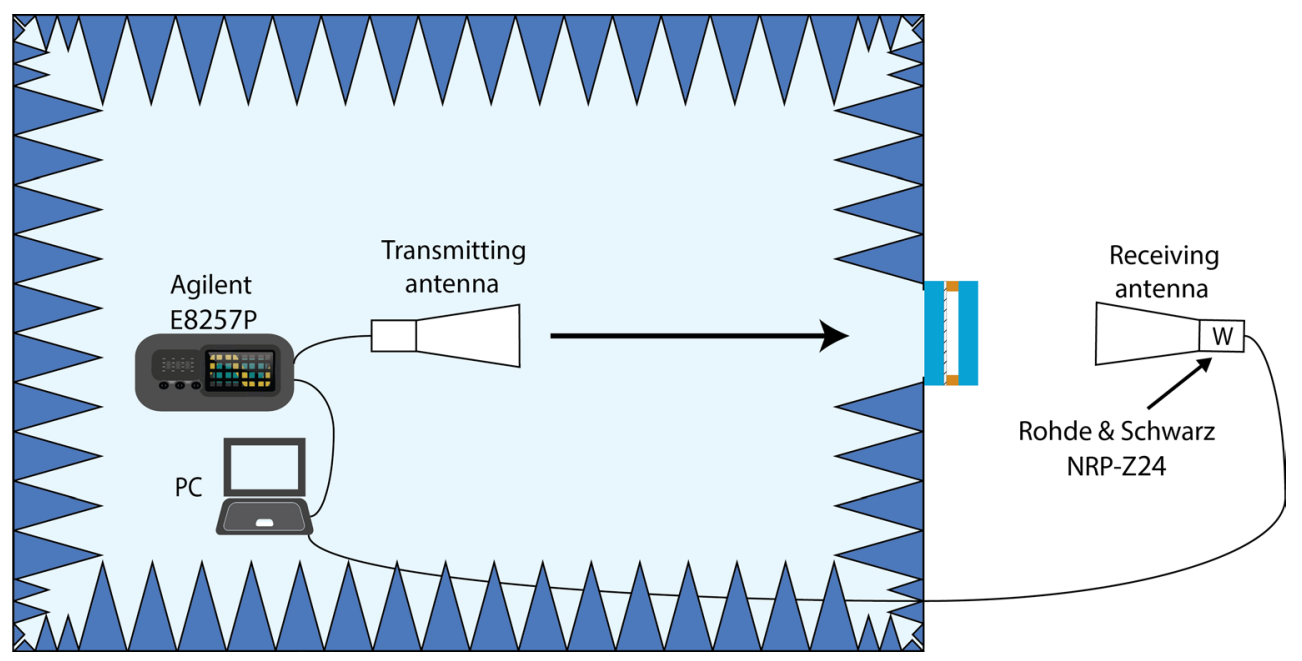

Fig. 1. Measurement layout in an anechoic chamber. 
was used to transmit a microwave signal. It was covered from the outside by the window under test. The size of the aperture was $28 \times 18 \mathrm{~cm}$ and the investigated samples were attached to its edge by means of a conductive and adhesive aluminum foil. The conductive foil covered only a few millimetres of the sample and it prevented leakage of microwaves between the sample and the wall. A transmitting antenna was placed approximately $130 \mathrm{~cm}$ from the aperture. It was connected to an Agilent E8257D microwave generator, which was controlled via a computer. The transmitting antenna, generator and computer were located in the anechoic chamber. The PC was also connected to a Rohde \& Schwarz NRP-Z24 power sensor, which was attached to the receiving antenna situated outside the chamber. Both transmitting and receiving antennas were broadband horn antennas LB-10180 with the frequency range from 1 to $18 \mathrm{GHz}$. Measurements were performed in the frequency range from 1 to $10 \mathrm{GHz}$. This range was chosen in order to cover both 2.4 and $5 \mathrm{GHz}$ WiFi frequency bands. The best way to assess transmission reduction is to use the parameter called SE, which describes the logarithmic ratio of power falling onto and power transmitted through the object under test. It can be expressed as

$$
\mathrm{SE}(f)=10 \times \log \left(\frac{P_{\text {air }}(f)}{P_{\text {glass }}(f)}\right),
$$

where $P_{\text {air }}$ is the power of microwave radiation transmitted through the aperture without the sample and $P_{\text {glass }}$ is the power transmitted through the aperture, with the sample. From Eq. (1) we can see that in order to measure SE two measurements should be made: one with and other without the sample.

The measured samples were made using Saint Gobain glass panes, the dielectric constant of all samples was $\varepsilon=6.5$. One of the glass panes had a conductive coating with the surface conductivity $\sigma=0.094 \mathrm{~S}$ (to avoid misinterpretation it is sometimes referred to as siemens per square). Surface conductivity of the glass was measured using the four-probe method. Additionally, the surface conductivity was also determined by fitting the calculated dependence of coated glass transmittance on frequency with the measured one. The dimensions of these glass panes are $30 \times 20 \mathrm{~cm}$, which means that they completely cover the aperture of the anechoic chamber. The Low-E or doubleglazed window was made by placing a Styrofoam board between the two glass panes and using an adhesive tape to hold everything in place. The adhesive tape was used because it does not attenuate microwaves and does not influence measurement results. The schematic view of a constructed window pane is shown in Fig. 2. Further in this paper any double-glazed window will be labelled in the following way: ' $4 \mathrm{~m}-10-4$ '. Here the first and last numbers show the thickness of glass panes in $\mathrm{mm}$, which means that, in this case, both glass panes are $4 \mathrm{~mm}$. The letter ' $\mathrm{m}$ ' denotes the interface on which a thin metal layer is deposited, therefore it indicates that the metal coating is on the inner side of a window pane. The middle number denotes the gap between the glass panes in $\mathrm{mm}$ and in our example it is $10 \mathrm{~mm}$.

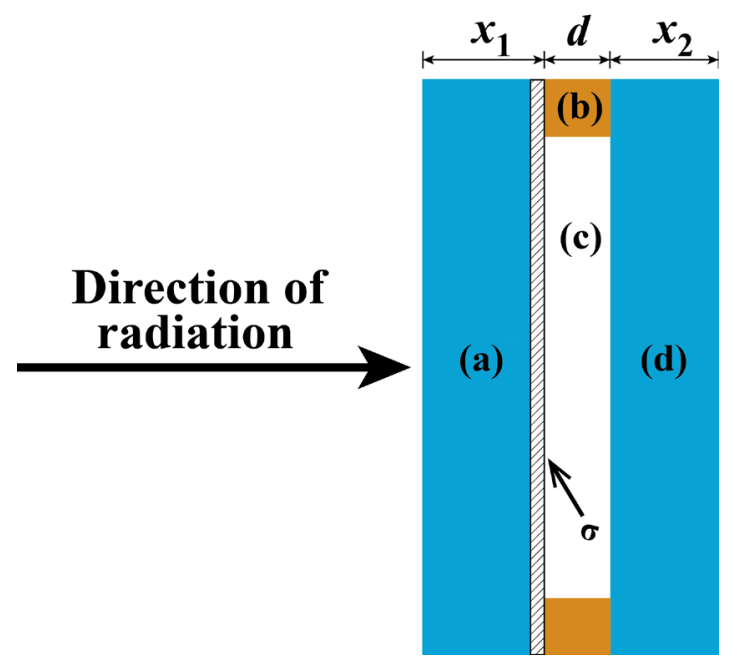

Fig. 2. The schematic view of a double-glazed window: (a) coated glass, (b) Styrofoam board, (c) air gap between the glass panes, (d) uncoated glass and a $\sigma$ conductive layer.

\section{Theoretical consideration}

The problem of a single metalized dielectric has been considered in [9], where the analytical formulas describing reflection and transmission of electromagnetic waves were derived. The aforementioned metal layer was characterized by an infinitely small thickness and the corresponding sheet conductivity $\sigma$. The interaction of the conductive sheet with electromagnetic wave was considered 
as a boundary condition leading to the break of the tangential component of a magnetic field [20]. The same approach was applied to the electromagnetic wave falling perpendicularly on a multilayered dielectric structure, where each interface might be covered with a thin metal layer [21]. The characteristic impedance $\eta_{i}$ is defined for each media by the equation $\eta_{i}=\eta_{0} \sqrt{\varepsilon_{i}}$, where $\eta_{0}$ is the impedance of free space and $\varepsilon_{i}$ is the relative permitivity of media. The thickness of the layer is $l_{i}$ and the propagation constant is $k_{i}=2 \pi \sqrt{\varepsilon_{i}} / \lambda$, where $\lambda$ is the wavelength in free space. Each interface is characterized by the surface conductivity $\sigma_{i}$. To calculate the transmitted wave amplitude through the conductive surface one can use the standard matching and propagation matrix method [22]. Taking into account the conductive layer on the $i$ th interface, the matching matrix will have the following form:

$$
M_{i}=\frac{1}{\tau_{i}}\left[\begin{array}{cc}
1+\alpha_{i} & \rho_{i}+\alpha_{i} \\
\rho_{i}-\alpha_{i} & 1-\alpha_{i}
\end{array}\right]
$$

Here $\alpha_{i}$ is the influence of conducting interface, $\rho_{i}$ and $\tau_{i}$ are the elementary reflection and transmission coefficients of the interface. These coefficients are expressed using the abovementioned characteristic impedances of different media in the following way:

$$
\rho_{i}=\frac{\eta_{i+1}-\eta_{i}}{\eta_{i+1}+\eta_{i}}, \tau_{i}=\frac{2 \eta_{i+1}}{\eta_{i+1}+\eta_{i}}, \alpha_{i}=\frac{\eta_{i+1} \eta_{i} \sigma_{i}}{\eta_{i+1}+\eta_{i}} .
$$

Three propagation matrices describing the propagation of electromagnetic wave within three different media of the double-glazed window are written down in a usual way [22]:

$$
P_{i}=\left[\begin{array}{cc}
\mathrm{e}^{\mathrm{i} k_{1} l_{1}} & 0 \\
0 & \mathrm{e}^{-\mathrm{i} k_{1} l_{1}}
\end{array}\right]
$$

Therefore to calculate, for example, the amplitude of transmitted wave through the doubleglazed window only multiplication of seven $2 \times 2$ matrices should be performed, four of which are matching and three are propagation. A more detailed explanation how SE can be calculated at an oblique angle of the incidence of electromagnetic wave can be found in [21, 22].

\section{Results and discussion}

\subsection{Dependence of SE on the gap between glass panes: theory and experiment}

Commercial Low-E windows are usually composed of two glass panes, $x_{1}=4 \mathrm{~mm}$ and $x_{2}=4 \mathrm{~mm}$, and the gap is $d=16 \mathrm{~mm}$. As shown in [21], they demonstrate a few minima of SE in the microwave frequency range. The simplest way to shift them in the frequency scale is to change the gap $d$ between glass panes. Therefore we manufactured windows with different $d$ using one metalized and one simple glass. We also calculated SE for such windows using the matrix multiplication method briefly described in Section 2. The experimental results together with the theoretically calculated data are shown in Fig. 3(a), where WiFi frequencies are marked by vertical lines. By comparing the Fig. 3(a) results with those of the commercial double-glazed windows presented in [21], it can be seen that our glass had a few times lower surface conductivity than the typical commercial glass. For this reason commercial windows show roughly $10 \mathrm{~dB}$ larger $\mathrm{SE}$ than home-made windows used in our experiments. It should be noted that the increase of $\sigma$ does not influence the positions of minimums, it only increases SE values by a certain amount in all frequencies evenly. As follows from the results presented in Fig. $3(\mathrm{a})$, the decrease of SE by a few $\mathrm{dB}$ at $2.4 \mathrm{GHz}$ and about $12 \mathrm{~dB}$ at $5 \mathrm{GHz}$ was achieved by changing $d$ only. Having a good coincidence between the measured and calculated results, further we shall use a numerical calculation in the optimization procedure. We try to elucidate in which way the thickness of glass panes and the gap between them influence the SE of the window.

We started from the dependence of SE on the gap $d$. The calculation results for a few values of the gap between glass panes are shown in Fig. 3(b). It is seen that by widening the gap $d$ between glass panes, SE minimums shift to lower frequencies. The minimum appearing at $3.5 \mathrm{GHz}$, when the gap is equal to $5 \mathrm{~mm}$, shifts to $1.5 \mathrm{GHz}$ at the $25 \mathrm{~mm}$ gap. The shielding minimum for $2.4 \mathrm{GHz}$ is obtained when $d=10 \mathrm{~mm}$. It should be noted that a second minimum appears while increasing the gap and it also shifts to lower frequencies when $d$ is growing. This peculiarity 

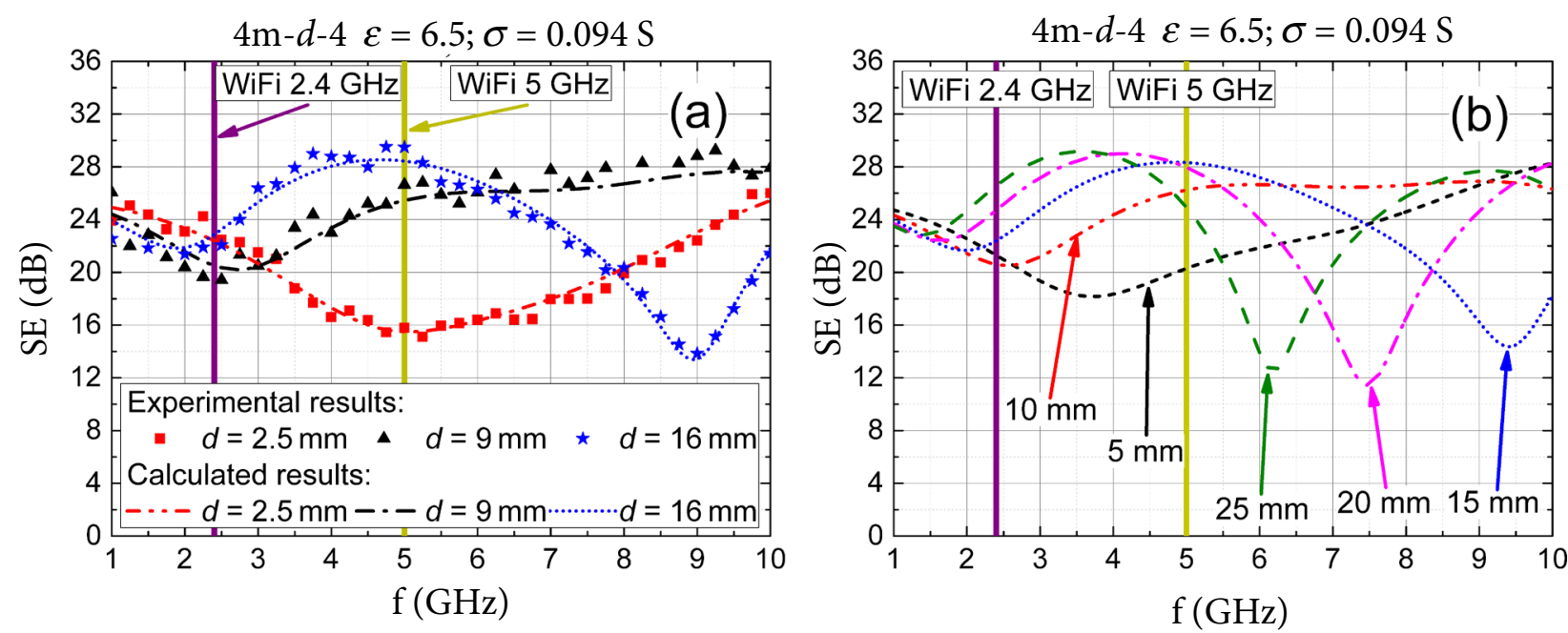

Fig. 3. Dependence of SE on the frequency for various gaps between glass panes $d$. Comparison of the experimental data (a) with calculation results (b). The parameters of windows are shown in the figure.

brought up an idea that when the conductivity of the metal layer is high enough, the wave, reflected from the last glass-air interface, bounces back and forth in the gap between the glass panes. By enlarging $d$, the optical length increases and the FabryPerot resonance shifts to lower frequencies. Our further investigations confirm this idea. At $5 \mathrm{GHz}$ frequency, we obtain the lowest SE of roughly $16 \mathrm{~dB}$, by lowering the gap down to $d=2.5 \mathrm{~mm}$. It should be noted that the $5 \mathrm{GHz}$ minimum can be obtained in two ways, either by shifting the first minimum while shrinking the gap or by moving the second minimum when increasing the gap over $d=25 \mathrm{~mm}$. Comparing the lowest $16 \mathrm{~dB}$ shielding value with SE of the standard doubleglazed Low-E window (blue curve online) the $12 \mathrm{~dB}$ decrease of SE was obtained. It is a rather big increase of window transparency at the $\mathrm{WiFi}$ frequency, however, the $2.5 \mathrm{~mm}$ gap is too small to provide a good thermal insulation. At $2.4 \mathrm{GHz}$ frequency it is possible to decrease SE by $2.5 \mathrm{~dB}$ compared to the standard window pane. This value is achieved with the gap $d=10 \mathrm{~mm}$.

On the one hand, it can be concluded that either the obtained decrease of SE is too small $(2.4 \mathrm{GHz})$ or the reduction of the SE spoils thermal insulation, since the gap between glass panes becomes too small $(5 \mathrm{GHz})$. On the other hand, it becomes clear that it is impossible to significantly reduce the SE of the window by changing only the gap between glass panes. Therefore, in the next Subsection we shall consider the influence of the thickness of glass panes on the SE of the window.

\subsection{Different thickness glass panes}

Let us separately consider the dependence of SE on the thickness of the coated and uncoated glass panes. The calculation results of such dependence on the thickness of the second glass are shown in Fig. 4(a). It is seen that at $x_{2}=1 \mathrm{~mm}, \mathrm{SE}$ monotonically decreases throughout the given frequency range. By increasing the thickness, two SE minimums start to appear in the considered frequency range. At $x_{2}=9 \mathrm{~mm}$, the third minimum turns up. Furthermore, every minimum shifts to a lower frequency range with the increase of glass thickness. It is evident that the dependence of SE on the thickness of the second glass behaves similarly as the dependence on the gap between glass panes. As follows from Fig. 4 (a), the first minimum can be set at $2.4 \mathrm{GHz}$ when $x_{2}=2 \mathrm{~mm}$ but the obtained SE $=22.6 \mathrm{~dB}$ is very close to the value of a standard window. It is also seen that the second minimum can be set at $5 \mathrm{GHz}$ using the uncoated glass thicker than $9 \mathrm{~mm}$.

The calculation results of SE for various thickness of the coated glass are shown in Fig. 4(b). It is seen that the behaviour of two SE minimums in the frequency scale differs from the cases considered earlier. The minimum SE appearing at $1.8 \mathrm{GHz}$ for $x_{1}=1 \mathrm{~mm}$ shifts to a higher frequency when the thickness of the coated glass is increased, whereas we saw the opposite dependence when the thickness of the second glass or the gap between glass panes was increased. By changing the coated glass thickness, one can get the $18 \mathrm{~dB}$ minimum value of SE for the $2.4 \mathrm{GHz}$ frequency with $x_{1}=10 \mathrm{~mm}$. 

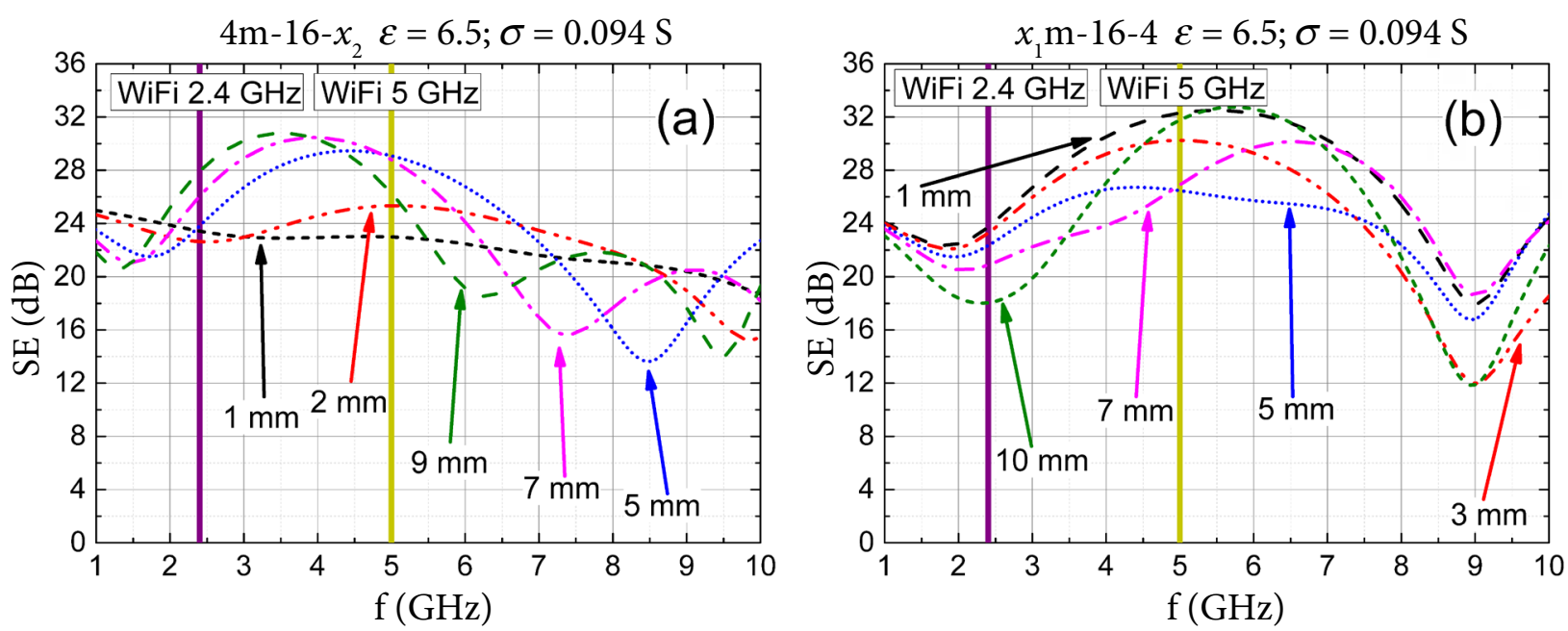

Fig. 4. The calculated dependence of SE on the frequency for various thickness of (a) uncoated glass and (b) coated glass for a double-glazed window.

A further increase of the coated glass thickness leads to the increase of SE of the first minimum that is not beneficial for the optimization procedure. There is other peculiarity of the dependence of SE on the coated glass thickness. The second minimum, which is around $9 \mathrm{GHz}$, does not shift with the increase of glass thickness, like in all previously considered cases. It seems that the position of the second minimum only depends on the optical path of microwave radiation through the air gap and uncoated glass. Coated glass metallization acts as a boundary, therefore, its glass thickness does not influence much the position of the second minimum. From these observations one can con- clude that in order to minimize the SE of a window pane at $2.4 \mathrm{GHz}$ frequency, coated glass needs to be thicker than in a standard window pane.

\subsection{Optimal longitudinal dimensions of the double- glazed window for the minimum of SE}

Using accumulated knowledge on the minimization of SE of a double-glazed window, now we shall determine the best parameters for the lowest possible $\mathrm{SE}$ at 2.4 and $5 \mathrm{GHz}$ WiFi frequencies. In Fig. 5 the dependence of SE on frequency for windows with standard longitudinal dimensions $4 \mathrm{~m}$ 16-4 is depicted by a red (online) short dash and for
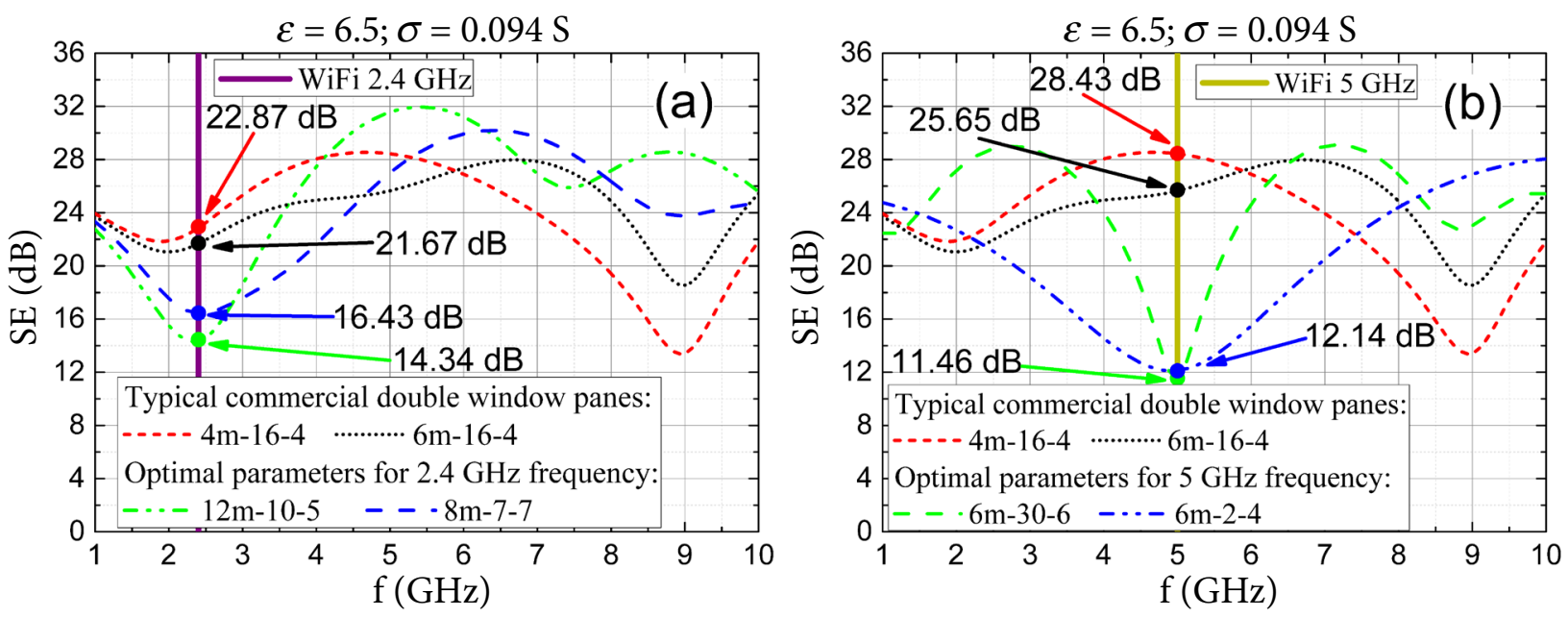

Fig. 5. Optimal double window pane longitudinal dimensions for (a) $2.4 \mathrm{GHz}$ frequency and (b) $5 \mathrm{GHz}$ frequency. 
6m-16-4 by a black dotted line. The optimization for $2.4 \mathrm{GHz}$ WiFi frequency is illustrated in Fig. 5(a). It can be seen that by changing longitudinal parameters, the calculated window panes have 7-9 dB lower SE at $2.4 \mathrm{GHz}$ frequency than standard ones. This was achieved by making thicker coated and uncoated glass panes, thus lowering the $\mathrm{SE}$ by several $\mathrm{dB}$ and shifting the resonant frequency below $2.4 \mathrm{GHz}$. After that, the gap is decreased up to $6 \mathrm{~mm}$ and it shifts the position of the minimum back to $2.4 \mathrm{GHz}$. Additionally, it reduces the value of SE at the WiFi frequency, achieving the 7-9 $\mathrm{dB}$ difference between the commercial and the optimized window. Even better results were achieved when minimizing SE at $5 \mathrm{GHz}$ frequency, those are presented in Fig. 5(b). A blue (dash dot dot) curve shows the maximum achieved reduction of SE without paying attention to the decrease of thermal insulation of the window. The calculation results for a more acceptable window, from the point of view of thermal isolation $(d=30 \mathrm{~mm})$, are shown in Fig. 5(b) by a green (dashed) line. It is seen that in both cases the achieved reduction of SE is roughly $14-17 \mathrm{~dB}$ at $5 \mathrm{GHz}$ frequency. These values are comparable with those obtained by FSS used for decreasing SE at WiFi frequencies [23].

\section{Conclusions}

The shielding effectiveness of energy saving windows was investigated both theoretically and experimentally. A good coincidence between the measured and calculated values of SE validates suitability of the matrix multiplication method for SE calculation of the energy saving windows having metallized glass. We found the optimal longitudinal dimensions of the energy saving windows for minimal SE values at WiFi frequencies. We demonstrated that by changing the thickness of the coated and uncoated glass panes along with the gap between them, the SE could be significantly decreased for WiFi frequencies. We achieved the 7-9 dB SE decrease for $2.4 \mathrm{GHz}$ and the $14-17 \mathrm{~dB}$ decrease for $5 \mathrm{GHz}$ in comparison with an ordinary energy saving window. The obtained SE reduction values are of the same order as those obtained using the frequency selective surfaces on metallized glass panes. This confirms that the variation of longitudinal dimensions is a perspective method for the reduction of SE in the mass production of window panes.

\section{References}

[1] European Commission. Energy Saving, https:// ec.europa.eu/energy/en/topics/energyefficiency/ buildings

[2] A. Asp, Y. Sydorov, M. Valkama, and J. Niemelä, Radio signal propagation and attenuation measurements for modern residential buildings, in: Proceedings of the 2012 IEEE Globecom Workshops (IEEE, 2012) pp. 580-584.

[3] M.D’Amore, D. Lampasi, M. Sarto, A. Tamburrano, V. De Santis, and M. Feliziani, Optimal design of multifunctional transparent shields against radio frequency electromagnetic fields, in: Proceedings of the 2009 Electromagnetic Compatibility Symposium Adelaide (IEEE, 2009) pp. 81-86.

[4] G.I. Kiani, A. Karlsson, L. Olsson, and K.P. Esselle, Glass characterization for designing frequency selective surfaces to improve transmission through energy saving glass windows, in: Proceedings of the 2007 Asia-Pacific Microwave Conference (IEEE, 2007) pp. 1-4.

[5] H. Tommerup, J. Rose, and S. Svendsen, Energyefficient houses built according to the energy performance requirements introduced in Denmark in 2006, Energy Build. 39(10), 1123-1130 (2007).

[6] R.B. Schulz, V. Plantz, and D. Brush, Shielding theory and practice, IEEE Trans. Electromagn. Compat. 30(3), 187-201 (1988).

[7] P. Ängskog, M. Bäckström, and B. Vallhagen, Measurement of radio signal propagation through window panes and energy saving windows, in: Proceedings of the 2015 IEEE International Symposium on Electromagnetic Compatibility (EMC) (IEEE, 2015) pp. 74-79.

[8] M. D’Amore, S. Greco, D. Lampasi, M. Sarto, and A. Tamburrano, A new structure of transparent films for heat control and electromagnetic shielding of windows, in: Proceedings of the 2009 International Symposium on Electromagnetic Compatibility - EMC Europe (IEEE, 2009) pp. 1-4.

[9] P. Ragulis, R. Simniškis, and Ž. Kancleris, Shift and elimination of microwave Fabry-Perot resonances in a dielectric covered with a thin metal layer, J. Appl. Phys. 117(16), 165302 (2015).

[10]H.-Y. Chen and T.-H. Lin, Dual-band frequency selective surface for improving the transmission 
of Bluetooth and WLAN signals through an energy-saving glass, J. Chin. Inst. Eng. 39(3), 331-336 (2016).

[11]G.I. Kiani, A.R. Weily, and K.P. Esselle, A novel absorb/transmit FSS for secure indoor wireless networks with reduced multipath fading, IEEE Microw. Wirel. Compon. Lett. 16(6), 378-380 (2006).

[12]T. Frenzel, J. Rohde, and J. Opfer, Elektromagnetische Schirmung von Gebäuden (BSI, Bonn, 2007).

[13]D.A. Lampasi, A. Tamburrano, S. Bellini, M. Tului, A. Albolino, and M.S. Sarto, Effect of grain size and distribution on the shielding effectiveness of transparent conducting thin films, IEEE Trans. Electromagn. Compat. 56(2), 352-359 (2014).

[14]Y. Corredores, P. Besnier, X. Castel, J. Sol, C. Dupeyrat, and P. Foutrel, Adjustment of shielding effectiveness, optical transmission, and sheet resistance of conducting films deposited on glass substrates, IEEE Trans. Electromagn. Compat. 59(4), 1070-1078 (2017).

[15]M. Gustafsson, A. Karlsson, A.P. Rebelo, and B. Widenberg, Design of frequency selective windows for improved indoor outdoor communication, IEEE Trans. Antennas Propag. 54(6), 18971900 (2006).

[16]S. Habib, M.F.U. Butt, and G.I. Kiani, Parametric analysis of a band-pass FSS for double glazed soft-coated energy saving glass, in: Proceedings of the 2015 International Symposium on Antennas and Propagation (IEEE, 2015) pp. 1-4.

[17]B. Widenberg and J.V.R. Rodríguez, Design of Energy Saving Windows with High Transmission at $900 \mathrm{MHz}$ and $1800 \mathrm{MHz}$, Technical Report LUTEDX/(TEAT-7110/1-14/(2002), Vol. TEAT7110 (Lund Institute of Technology, 2002).

[18]S.I. Sohail, G. Kiani, and K. Esselle, Parametric analysis of RF and microwave transmission through single and multiple layers of float glass, in: Proceedings of the Asia-Pacific Microwave Conference 2011 (IEEE, 2011) pp. 1454-1457.

[19]B. Foulonneau, F. Gaudaire, and Y. Gabillet, Measurement method of electromagnetic transmission loss of building components using two reverberation chambers, Electron. Lett. 32(23), 2130-2131 (1996).

[20]Ž. Kancleris, G. Šlekas, and A. Matulis, Modeling of two-dimensional electron gas sheet in FDTD method, IEEE Trans. Antennas Propag. 61(2), 994-996 (2013).

[21]P. Ragulis, P. Ängskog, R. Simniškis, B. Vallhagen, M. Bäckström, and Ž. Kancleris, Shielding effectiveness of modern energy-saving glass panes and windows, IEEE Trans. Antennas Propag. 65(8), 4250-4258 (2017).

[22]S.J. Orfanidis, Electromagnetic Waves and Antennas (Rutgers University, New Brunswick, NJ, 2002).

[23]S.I. Sohail, K.P. Esselle, and G. Kiani, Design of a bandpass FSS on dual layer energy saving glass for improved RF communication in modern buildings, in: Proceedings of the 2012 IEEE International Symposium on Antennas and Propagation (IEEE, 2012) pp. 1-2.

\title{
ENERGIJĄ TAUPANČIŲ LANGŲ EKRANAVIMO EFEKTYVUMO MINIMIZACIJA WiFi DAŽNIŲ RUOŽE
}

\author{
E. Bilotas, P. Ragulis, Ž. Kancleris \\ Fiziniu ir technologijos mokslu centras, Vilnius, Lietuva
}

\section{Santrauka}

Teoriškai ir eksperimentiškai ištyrinèta šiuolaikinių energiją tausojančių stiklo paketų elektromagnetinių bangų pralaidumo mikrobangų dažnių ruože priklausomybė nuo išilginių lango matmenų (stiklų storio ir tarpo tarp jų dydžio). Keičiant stiklo paketo išilginius matmenis, ekranavimo efektyvumo minimumas gali būti nukreiptas ị pageidaujamą dažnių ruožą. Pademonstruota, kad pakeičiant tik stiklo paketo išilginius matmenis, bevielio ryšio $(\mathrm{WiFi})$ signalo stiprumą per stiklo paketus galima padidinti 7-9 $\mathrm{dB}(2.4 \mathrm{GHz}$ ruože $)$ ir net $14-17 \mathrm{~dB}$ (5 GHz ruože), palyginti su standartiniais langų paketais. Teorinius ekranavimo efektyvumo skaičiavimus patvirtino eksperimentiniai tyrimo rezultatai, atlikti parenkant atitinkamą stiklų ir tarpo tarp jų storị. 